\title{
A block model of the production process of winter wheat based on yield-protein values
}

\author{
Natalya P. Bakaeva* \\ Samara State Agrarian University, Kinel 446442, Samara region, Russia
}

\begin{abstract}
Due to the complex production process, its block model simplified for practical purposes is presented for winter wheat. The model allows for predicting the yield and providing recommendations on the optimal fertilizer application, quality, nature and quantity of fertilizers. The interconnections and interdependences of the production process values were studied on the basis of the long-term experiment on winter wheat cultivation using the method of correlation analysis. The yield and protein values can be used individually and in combination based on the requirements for the production process of winter wheat in the Middle Volga region.
\end{abstract}

\section{Introduction}

The basis of the plant production process model is based on complex processes; to simplify them, one can narrow down issues based on the purpose of the model under consideration. The study of possible responses of plants to growing conditions can be limited to the construction of models with a block structure. Each block describes homogeneous physical, biophysical, biochemical or physiological processes in separate parts of the soilplant-weather system. The reduction of such blocks to the level of several disparate factors acting unidirectionally on the same signs is also possible; such a block model can be verified, checked for accuracy by selecting factors and their relationship and interdependence [1].

The crop model can be represented as a crop of cereals. The model forecasts the crop yield under certain weather conditions or provides recommendations on the optimal application, quality, nature and quantity of fertilizers. The interconnections and interdependences of the production process values were studied on the basis of the long-term experiment on winter wheat cultivation [2].

\section{Materials and methods}

\subsection{Objects}

The objects were winter wheat variety Povolzhskaya 86, elite seeds were used for sowing. Pre-sowing seed treatment was carried out with micronutrient fertilizers of copper $33-38 \mathrm{~g} / \mathrm{dm}^{3}$, boron $5.5-5.7 \mathrm{~g} / \mathrm{dm}^{3}$, molybdenum $14-22 \mathrm{~g} / \mathrm{dm}^{3}$, zinc $35-40 \mathrm{~g} / \mathrm{dm}^{3}$, (3 1 of the preparation per 71 of water per $1 \mathrm{t}$ of seeds) [3]. The following organic fertilizers were used for presowing application: manure containing organic matter 75-90\%, including humic acids, nitrogen - $20 \%$, other components [4]. Liquid organic fertilizers are produced from chicken manure and animal waste. Mass fraction of total nitrogen was $0.28 \%$. Dry organic fertilizers are treated crop waste. The mass fraction of total nitrogen was $5.28 \%$.

Early spring treatment with mineral nitrogen fertilizers was carried out in the first decade of April with ammonium nitrate, ammonium sulfate and urea. Fertilizer doses were applied based on N40.

The purpose is to build a block model for yieldprotein values which forecasts the crop yield under certain weather conditions or provides recommendations on the optimal application, quality, nature and quantity of fertilizers.

The research objectives are to assess yield-protein values in the block model of winter wheat cultivation, depending on the application of fertilizers, their quality, nature and quantity.

\subsection{Methods}

The study was conducted in the central zone of Samara region in 2010-2015, on the experimental fields of the Department of Land Management, Soil Science and Agricultural Chemistry of Samara State Agrarian University. The terrain was leveled, the soil of the experimental field was a typical medium humus, a medium heavy loamy chernozem. The area of the plots was $270 \mathrm{~m}^{2}(9 \times 30 \mathrm{~m})$, the repetition was threefold, the distribution of the plots was systematic, single-tier. The predecessor was black fallow. Humidification was natural. Widespread agricultural technologies were used [5]. Sowing was carried out in an ordinary way with the DMS 601 seeder to a depth of 6-8 $\mathrm{cm}$ with a seeding rate of 5.0 million germinating seeds/ha. The agrochemical

\footnotetext{
* Corresponding author: bakaevanp@mail.ru
} 
parameters of the soil were as follows: nitrate nitrogen $4.47 \mathrm{mg} / \mathrm{kg}$, easily hydrolyzed nitrogen $-42.4 \mathrm{mg} / \mathrm{kg}$, organic matter $-4.6 \%, \mathrm{P}_{2} \mathrm{O}_{5}-96.8, \mathrm{~K}_{2} \mathrm{O}-86.6 \mathrm{mg} / \mathrm{kg}$, $\mathrm{pH} 7.82$ [6].

According to the weather station in Ust-Kinel, meteorological conditions were unstable. In 2010, weather created a strong desiccation of soil by the time of sowing winter wheat. In the third decade of August, precipitation $(28 \mathrm{~mm})$ created moistening of the upper soil layer and ensured seed germination and emergence of seedlings. There were no dangerous weather autumnwinter phenomena.

During the period of active growth of winter wheat, winter conditions were favorable. The weather conditions were as follows. In 2011, the hydrothermal coefficient was 1.2; vegetation conditions of the agricultural year were humid with an average long-term HTI of 0.83 . In 2012, the duration of the period of active vegetation was 185 days, which was 37 days longer than usual; it was characterized by hot weather without effective precipitation - atmospheric drought, the hydrothermal coefficient of SCC was below 0.6.

2013 was favorable for the growth and development of winter wheat. The HTI was 1.07, however, the arid conditions in May, June, and most of July did not contribute to the good crop yield. The conditions of the growing season of 2014 were very dry, the hydrothermal coefficient was 0.34, atmospheric drought in July and early August did not favor grain formation.

In 2015, there was an increased temperature regime and a small amount of precipitation, the HTI was 0.7. Only in 2013 the HTI was equal to 1.07; however, with optimal moisture, arid conditions did not contribute to the good crop yield.

Productivity was determined by harvesting the accounting area of the plot $\left(50 \mathrm{~m}^{2}\right)$ with a TERRION selection combine in the phase of full ripeness of grain. Crop accounting was carried out according to the method of the State Commission for Variety Testing. The attracting ability of the spike was determined by the ratio of the weight of the spike in the ripening phase (full ripeness) to its weight in the flowering phase.

The spike implementation coefficient (SIC) was determined as an increase in the spike mass during the period from the flowering phase to the ripening phase [4, $7,8]$. Biochemical studies were carried out according to the described methods [1, 2], plants for analysis were selected according to E.A. Ermakov (1987), protein fractions were isolated according to Kh.N. Pochinok (1976), quantitative protein content was determined by the colorimetric method according to G.A. Kochetov (1971) [2].

All other observations and related studies were carried out according to the relevant methods of the State Commission and GOST methods. The experiments were triplicate. Statistical processing of yield data was carried out by the analysis of variance using the STATISTICA program. The experimental design is presented in Table 1.

\section{Results}

We studied the components of the block model implemented by the yield and protein content in winter wheat, depending on various types of fertilizers.

Attraction is the most important property of plants to attract plastic substances to zones and centers of growth processes. The size (mass) of ripened grain, the size and yield of the economic yield in plants depend on the level of attraction of the products of photosynthesis [4]. In wheat, the spike's attracting ability is determined by the ratio of the weight of the spike in the ripening phase (full ripeness) to its weight in the flowering phase. An increase in the mass of an ear during the period from flowering to ripening is called the spike implementation coefficient (SIC) [7, 8]. The attracting ability and the SIC for Povolzhskaya 86 variety are presented in Table 1.

The greatest ability to attract substances was manifested when pre-sowing with organic fertilizers (48\%). A less significant amount of attraction was manifested when applying mineral fertilizers $(37 \%)$, and for pre-sowing treatment $(33 \%)$.

The spike implementation coefficients for the presowing treatment and application of organic fertilizers were equal, and exceeded the control value by $51 \%$. The application of nitrogen fertilizers increased this value by $35 \%$.

The value of the winter wheat crop for the five-year study period was the largest when applying organic and mineral fertilizers $(31 \%)$; micronutrient fertilizers increased the yield by $17 \%$.

The application of fertilizers affects physiological parameters: the grain size, mass of 1000 grains. It is necessary to determine the yield of protein per 1000 grains. So, when applying organic and mineral fertilizers, this indicator was the largest exceeding the control one by $17 \%$. A lower value of the protein yield was when applying microfertilizers (an increase by $11 \%)$.

The protein content can vary. The options showed that the greatest increase was when applying nitrogen fertilizers $(15 \%)$. Presowing treatment with organic fertilizers increased the protein content by $12 \%$, and micronutrient treatment - by $3 \%$.

The combined application of copper and zinc during the pre-sowing treatment with microfertilizers increased all other studied parameters: a $2 \%$ increase in yield compared with the use of copper and molybdenum, a $4 \%$ increase compared with copper and boron.

Among organic fertilizers, the highest values were observed when applying manure. The yield increased by $3 \%$ relative to the average, the protein content increased by $6 \%$.

The nitrogen fertilizers increased the yield and protein content. Ammonium sulfate significantly increased the attracting ability of spikes, urea increased the SIC by $17 \%$, ammonium nitrate in the protein yield of 1000 grains - by $2 \%$. 
Table 1. The components of the block model implemented in average winter wheat yield and protein values depending on the fertilizer used for the period under study

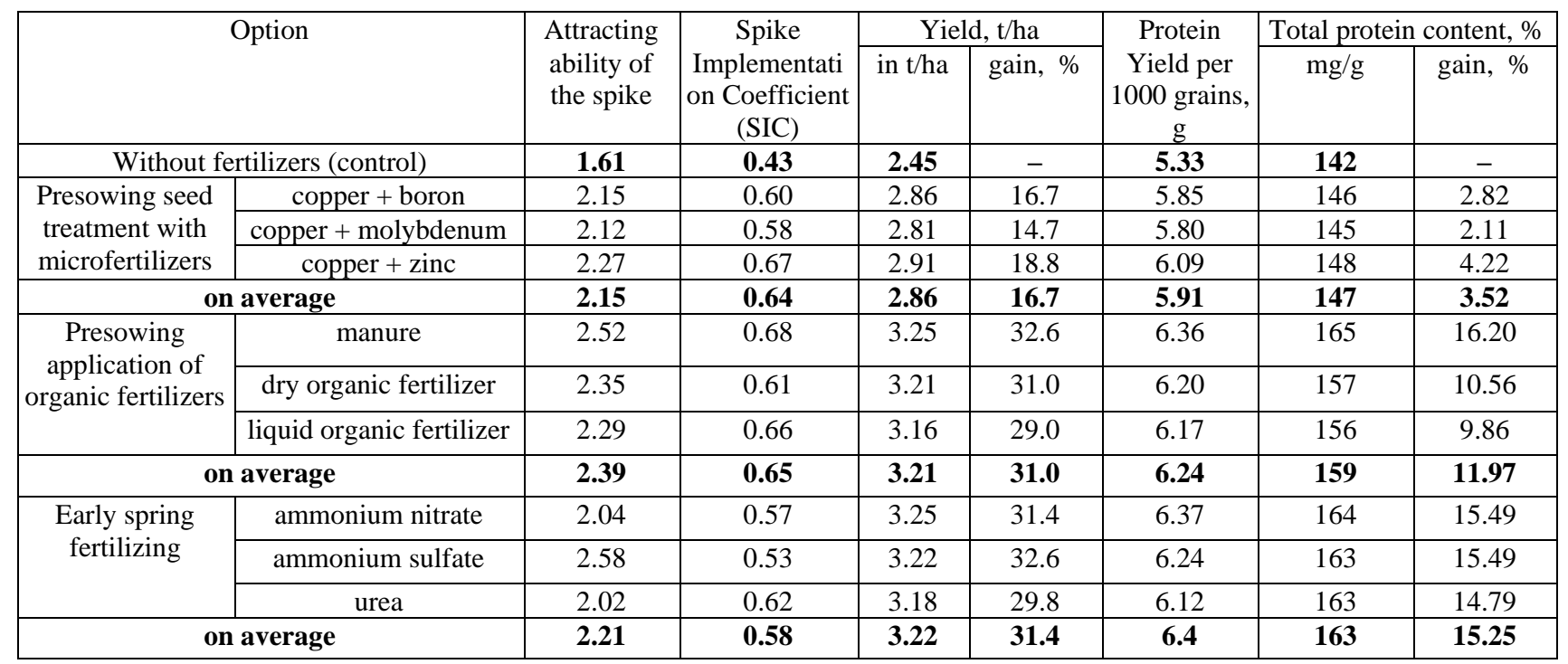

Modern fertility models include agrochemical, physical, biological, and other indicators that allow us to evaluate and predict the level of the production process of agricultural plants. Our model indicates the method of application, the nature and dose of fertilizers for the implementation of a stable production process.

Quantitative and qualitative measures for the implementation of stability mechanisms are components of the block model (yield-protein indicators presented in Table 1 which provide steady increases in yield and protein content values confirmed by five-year studies).

The most promising way to increase grain yield is to increase the share of grain mass in relation to the plant and spike [9]. Under optimal growing conditions, on average, during the research period, the proportion of the mass of grain was $36 \%$ of the mass of the plant and $68 \%$ of the weight of the ear.

The correlation analysis can show the relationship between the signs by measuring the average value of the effective sign depending on the value of the factor or factors [10]. Moreover, changes in one or more quantities lead to a systematic change in other quantities. The mathematical measure of the correlation of two random variables is the correlation coefficient - this is an indicator of the nature of changes in two random variables.

The correlation can be positive and negative. Negative correlation is a correlation in which an increase in one variable is associated with a decrease in another variable, while the correlation coefficient is negative. With a positive correlation, an increase in one variable causes an increase in another variable, while the correlation coefficient is positive.

For the indicators of the block model, we determined the correlation between the indicators using the correlation method and described the form of this connection using the regression equations.

Table 2 presents the results of calculating the correlation coefficients and regression equations.
Table 2. Correlation coefficients and the degree of dependence of the yield and protein content

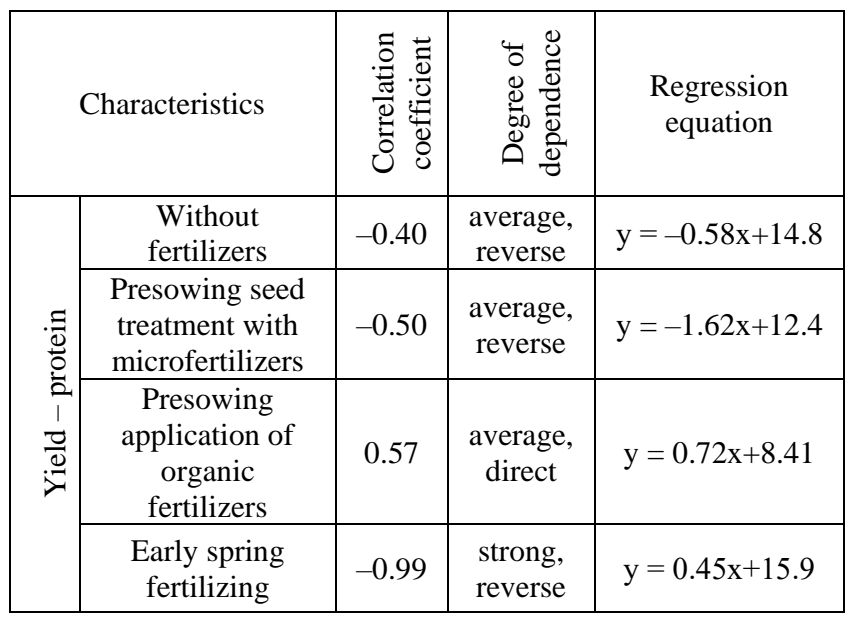

The correlation coefficients show that the degree of dependence between the yield and protein content in winter wheat grain Povolzhskaya-86 are average or strong, both direct and reverse. The determination coefficient in the regression equation is close to 1 ; therefore, the linear regression equations describe the existing dependence of the characteristics.

In the control option without fertilizers, the correlation coefficient of the characteristics of the block model yield-protein is $r=-0.40$, and was smaller than in the other options. The option "pre-sowing seed treatment with micronutrient fertilizers" was closer by the correlation coefficient, the degree of dependence and determination coefficients in the regression equation of the studied characteristics, $r=-0.50$, the relationship according to the Cheddock score is average, reverse.

The negative correlation and the negative correlation coefficient show that an increase in one indicator (e.g., yield) causes a decrease in another indicator (e.g., protein content), and vice versa. 
In the option "pre-sowing treatment with organic fertilizers", a positive correlation coefficient equal to $\mathrm{r}=$ 0.57 was obtained.

A positive correlation is a correlation in which an increase in one indicator is due to an increase in another one. The yield will increase and a decrease in protein content is not observed. The degree of dependence is average, direct. This interdependence is represented by the regression equation, the determination coefficient is 0.8 .

Early spring fertilizing with mineral fertilizers influenced the performance of the yield-protein block model. The correlation coefficient is -0.99 , the dependence is strong and reverse. This state of the indicators of the correlation coefficient and the tightness of the relations of the signs show that an increase in one indicator is associated with a decrease in another indicator - yield and protein content.

The determination coefficient is more than 1 ; therefore, the linear regression equations describing the existing dependence of the studied traits show the share of other influences (for example, weather conditions).

\section{Discussion}

When comparing the indicators of the attracting ability and the spike implementation coefficient according to the experimental options depending on the applied micronutrient fertilizers, organic fertilizers and nitrogen fertilizing, the highest value of these indicators is noted in the option "pre-sowing treatment with organic fertilizers" - by $48 \%$ and $51 \%$ higher than in the control option.

The main indicator of the block model is a yield; an increase in the yield and protein content per 1000 grains in the control option were the smallest; the effect of organic and mineral fertilizers was equal and increased these indicators by $31 \%$ and $17 \%$, respectively.

The highest results were observed when fertilizing with nitrogen fertilizers - an increase by $15 \%$.

Thus, the correlation analysis carried out for the characteristics of the yield-protein block model revealed average and strong, direct and reverse degrees of dependence. Options without fertilizers and pre-sowing treatment with micronutrient fertilizers had an average and reverse degree of dependence, the correlation coefficients were $r=-0.40 \ldots-0.50$, respectively. Early spring fertilizing showed a high correlation coefficient equal to $r=-0.99$.

The interdependence of the signs is strong and reverse, and other possible influences, for example, changing weather conditions, are determined by the regression equation. Despite the average interdependence of traits, the option "presowing treatment with organic fertilizers" was direct; the determination coefficient is close to 1 ; therefore, these analysis elements characterize the existing dependence of the studied traits.

\section{Conclusion}

Studies of the main indicators of the block model - yield and protein content - and the effect of fertilizers showed that it is not unique. An increase in the yield was $17 \%$; application of copper and zinc increased the yield by $19 \%$ and protein content - by $3 \%$ and $4 \%$, respectively. The pre-sowing application of organic fertilizers increased the yield and protein indicators; the application of manure increased them by $33 \%$ and $16 \%$, respectively. Each of the nitrogen fertilizers affected different indicators; ammonium nitrate increased the yield, protein yield of 1000 grains and protein content; ammonium sulfate - the attracting ability; urea - the spike implementation coefficient.

Thus, under the prevailing weather conditions, the fertilizers which differ in the application method, quality, and nature, had a positive effect on the yield and protein values. They can be used both individually and in combination, based on the requirements for the production process of winter wheat in the Middle Volga region.

The average negative correlation between yield and protein content in the control option and in the option "pre-sowing seed treatment with micronutrient fertilizers" is explained by the antagonism of these traits in wheat due to its vegetation conditions (moisture, heat, light exposure) and the impossibility of obtaining high yields with a sufficiently high protein content. The strong reverse dependence indicates the dependence of these signs and the influence of other factors, such weather conditions during the growing season of winter wheat.

This shows the high demand of this crop for early spring fertilizing with mineral fertilizers. The opposite values of the degree of dependence are observed during the pre-sowing application of organic fertilizers, and the determination coefficient in the regression equation is close to 1; therefore, these analysis elements characterize the existing dependence of the studied characteristics.

\section{References}

1. N.P. Bakaeva, O.L. Saltykova, Manifestation of the protein complex of wheat grains of various agricultural technologies of the Middle Volga region 157, (Kinel, 2018).

2. N.P. Bakaeva, Bull. of Ulyanovsk State Agricultural Academy 4(44), 71-76 (2018)

3. S.N. Zudilin, Innov. achievements of sci. and techn. of the agro-industrial complex 135-137 (2018)

4. N.Yu. Korzhavina, Contribution of young scientists to the agricultural science of the Agricultural Academy 88-89 (2016)

5. A.A Zavalin, Agricultural chemistry 5, 20-26 (2014) 
6. O.L. Saltykova, Contribution of young scientists to the agricultural science of the Agricultural Academy 39-43 (2013)

7. V.I. Polonsky, Bull. of KrasSAU 4, 58-64 (2009)

8. M.M. Rakhimov, DAN RT 6, 504-507 (2011)
9. Yu.A. Gulyanov, Izvestia OSAU 37(1), 45-49 (2012)

10. E.N. Pasynkova, Achievements of science and technology of agribusiness 9, 27-29 (2012) 